\title{
Dynamic Analysis of Load Lifting Machines and Correlation With Measurement Results
}

\author{
Jovan Vladić ${ }^{*}$, Radomir Đokić ${ }^{1}$, Hotimir ml. Ličen ${ }^{2}$ \\ ${ }^{1}$ Facuty of Technical Sciences, University of Novi Sad (Serbia) \\ ${ }^{2}$ TRC PRO d.o.o., Petrovaradin (Serbia)
}

The paper presents the issues with the dynamic analysis of vertical transport machines, like mine elevators, used with underground exploitation of raw materials. Dynamic occurrences are particularly emphasized with those elevators due to the fact that they are facilities with extreme heights (up to $2000 \mathrm{~m}$ ) and lifting speeds (up to $20 \mathrm{~m} / \mathrm{s}$ ) using the steel ropes. It shows the forming path of a competent dynamic model for the analysis of such elevators. Basic parameters (stiffness and damping) are of variable magnitude during the lifting, so their values are defined through a combination of theoretical analysis and performed experiments at mine elevators in real conditions.

Keywords: Machines for vertical transport, dynamic models, stiffness, damping

\section{INTRODUCTION}

Advancements of the science and technological development, as well as the demands concerning capacity increase, have consequently developed a need for vertical transport machines with the velocities up to $20 \mathrm{~m} / \mathrm{s}$ and with pronounced dynamic loads, what causes a problem of the right choice and definition of basic parameters of the facilities, especially regarding their reliability, i.e. operating safety.

Some of hoisting devices are the mine elevators, which are used to interconnect different mine horizons by using a mine cage (which is moved between at least two firmly set guide rails), whose dimensions and construction enable ore loading and are approachable to people.

The mines use two systems, one with a drum and the other with a driving pulley (Koepe system). Fig. 1 provides a scheme of the most applied lifting systems in mine facilities with a driving drum and a friction mechanism (Koepe system)

In the systems with a lifting drum, the carrying ropes are wound and stored on a drum. The lifting system with one drum (Fig. 1a, 1b), due to the heavy load and a necessary big length of the drum, is less applicable. However, the system with two drums (Fig. 1c) allows lifting of two separate "loads" in the same shaft (e.g. one "load" can be a cabin, and the other counterweight, which is the case with standard elevators, or there are many instances in the mines when both of the "loads" can be "useful" - one cabin is being lifted while the other is being lowered). The drums are located in the machine room which is usually sideways of the mine shaft, and the ropes go down from it over the deflector pulleys into the shaft next to the cabin. The multi ropes lifting system (Fig. 1d, 1e) with the mine elevators is actually a variation of the lifting system with two drums. They are used for bigger loads and in relatively deep pits.

Friction lifting systems (Koepe) are mostly used in European mines. The drive is set above (Fig. 1g) or sideways to the mine shaft. In the case when it is located sideways (Fig. 1f) deflector pulleys are used and they are set above the mine cage (cabin) and the counterweight. The main advantages of the system are decreasing of a driving motor, i.e. necessary torque, a simpler usage of a higher number of steel ropes and the possibility of setting the driving pulley directly above the mine shaft. However, due to the limitations in contact pressure $(1,75 \mathrm{MPa})$ and the limits of slipping $\left(S_{1} / S_{2} \leq 1,4\right)$ between the ropes and the pulley, the advantages are lost, so in practice both systems are applied almost equally.

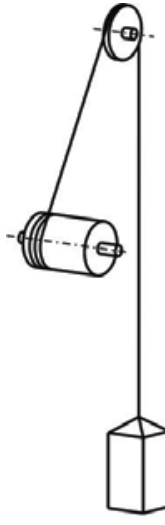

a)

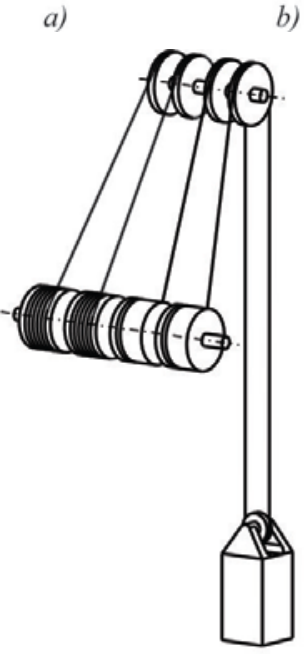

e)

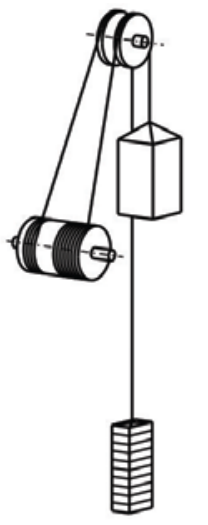

b)

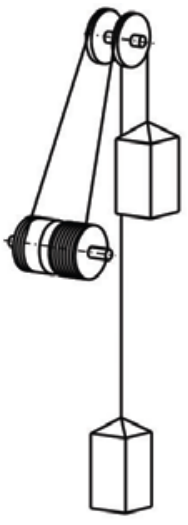

c)

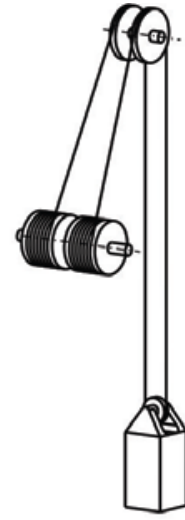

d)

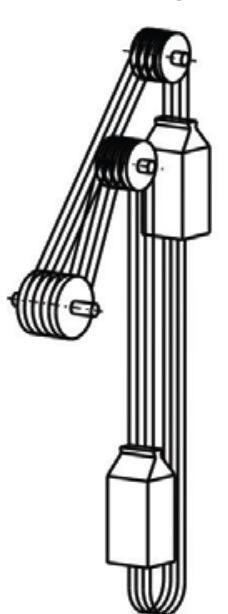

f)

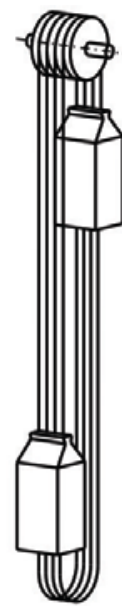

g)
Figure 1: Lifting systems with a drum and Koepe system 


\section{FORMING A SUITABLE MODEL FOR THE DYNAMIC ANALYSIS OF VERTICAL TRANSPORT MACHINES}

As it was mentioned before, the characteristic features of mine elevators are reflected in high lifting heights up to $2000 \mathrm{~m}$ and the velocity up to $20 \mathrm{~m} / \mathrm{s}$ [4]. The basic dynamic model for this system is shown in Fig. 2a. Nevertheless, if one looks at the regular operation of the facility, without the slipping of the steel rope in a driving pulley, and if as the driving characteristic is accepted rope velocity at the moment of rope upcoming the pulley (measuring the velocity of the pulley), the model of the mine elevator can be represented in the form shown in Fig. $2 b$.

This model shows a system with longitudinal oscillations of a "heavy" steel rope with an infinite number of degrees of freedom (DOF), which is at one end wound onto a pulley at a velocity $v(\mathrm{t})$, while it is loaded with a concentrated mass on the other end. Forming a representative model for the analysis of dynamic behaviour implies simplification of the model so as to exclude the small influences of the "higher" order and to keep only the most influential (representative) parameters [8].

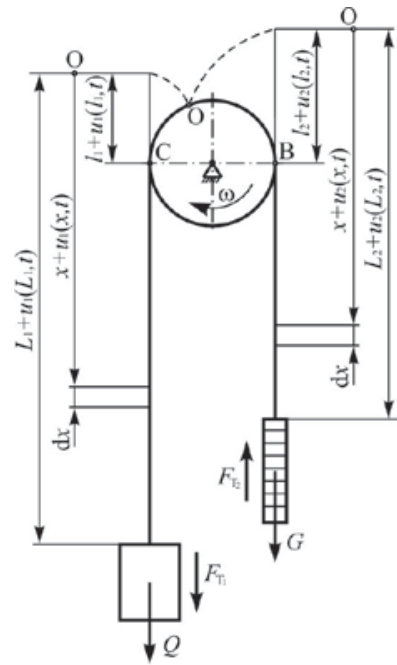

a)

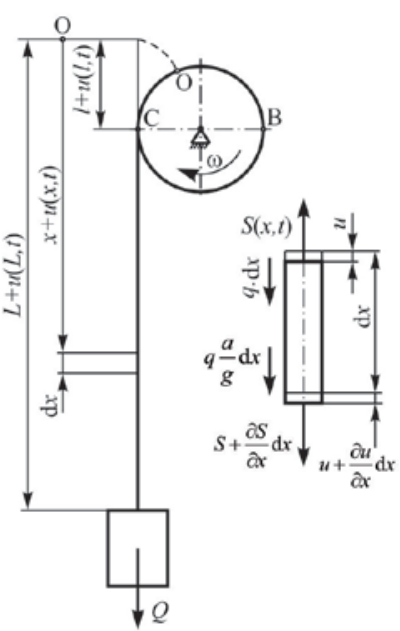

b)
Figure 2: Oscillation of the constant length rope, basic model (a), reduced model (b)

2.1. Reduction of the number of degrees of freedom

Deformation of the arbitrary cross section is represented as a function of position $\mathrm{x}$ and time $\mathrm{t}$, i.e.:

$$
u=f(x, t)
$$

By observing the balance of the elementary part $(\mathrm{d} x)$ it can be noted that:

$$
\frac{q \cdot \mathrm{d} x}{g} \cdot \frac{\partial^{2} u(x, t)}{\partial t^{2}}=-S+S+\frac{\partial S}{\partial x} \mathrm{~d} x+q \cdot \mathrm{d} x \pm \frac{q \cdot \mathrm{d} x}{g} \cdot a
$$

If the axial force $S$ is described as a relative deformation function $\varepsilon=\partial u / \partial x$, for the case of damping oscillations:

$$
S=E \cdot A \cdot \frac{\partial}{\partial x} \cdot\left[1+b \cdot \frac{\partial}{\partial t}\right] \cdot \varepsilon
$$

$\frac{\partial^{2} u(x, t)}{\partial t^{2}}=\frac{g \cdot E \cdot A}{q} \cdot \frac{\partial^{2}}{\partial x^{2}}\left(u(x, t)+b \cdot \frac{\partial u(x, t)}{\partial t}\right)+g-a$

with:

$E$ - elasticity modulus, $\mathrm{MPa}$

$A$ - rope cross-section, $\mathrm{mm}^{2}$

$u$ - rope elastic deformations, $\mathrm{mm}$

$b$ - damping parameter, Ns/m

$q$ - rope weight pro meter, $\mathrm{N} / \mathrm{m}$

$a-$ driving mechanism acceleration (at the point where the rope meets the driving pulley), $\mathrm{m} / \mathrm{s}^{2}$

In order to define the oscillation forms we shall observe the simplified (4) without two last parts on the right side, which corresponds to the rope oscillation after stopping the pulley. In that case the solution to the equation can be seen as a multiplication of the two functions, where one is a position function and the other is a time function [5], in the following form:

$$
u(x, t)=X(x) \cdot T(t)
$$

If we take $\frac{g \cdot E \cdot A}{q}=c^{2}$, where (c) is the propagation velocity of the elastic wave throughout the rope, the (5) is differentiated in time and place, and it is inserted in the simplified (4), so we perform the separation of the variables, and we get that:

$$
\frac{\ddot{T}}{c^{2}(T+b \cdot \dot{T})}=\frac{X^{\prime \prime}}{X}=-k^{2}
$$

where $(k)$ is the constant which is independent of time and position. That evolves into two common differential equations:

$$
\begin{aligned}
& \ddot{T}+b \cdot k^{2} \cdot c^{2} \cdot \dot{T}+k^{2} \cdot c^{2} \cdot T=0 \\
& X^{\prime \prime}+k^{2} \cdot X=0
\end{aligned}
$$

A more detailed solving procedure of differential equations with boundary conditions is provided in $[4,10]$. The solution to the other equation defining the basic oscillation forms of specific harmonics is as follows:

$$
X(x)=A_{i} \cdot \sin \beta_{i} \cdot \frac{x-l}{L-l}
$$

where we get a frequency equation in the form of:

$$
\beta_{i} \cdot \operatorname{tg}\left(\beta_{i}\right)=\alpha
$$

with:

$$
\begin{aligned}
& \beta_{i}=k \cdot(L-l) \\
& \alpha=\frac{q \cdot(L-l)}{Q} \text { - represents the weight ratio between the }
\end{aligned}
$$

rope's free length and the car.

For different ratios of the rope weight and the load it is possible to find the solutions for the transcendental (9) by using the calculation methods or graphically. It has an infinite number of roots, therefore the number of its own circular frequencies is indefinitely large.

A small weight of the rope's free length in comparison to the concentrated mass greatly simplifies the analysis of the dynamic behaviour of mine elevators.

and if the (2) is divided with $\frac{q \cdot \mathrm{d} x}{g}$, we get: 


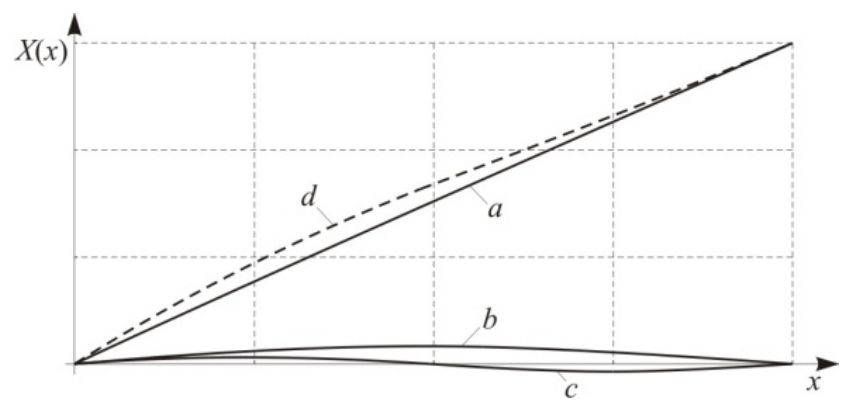

Figure 3: The oscillations forms of the first three harmonics $(a, b$, and $c)$ and the collective oscillation form for $\alpha=0,1$

Due to the fact that oscillation amplitudes of higher harmonics are rather small, their influence can be neglected, so the whole oscillation process, represented in (4) with an infinite number of DOF, whose collective oscillation form is shown in Fig. 3 as a broken line (d), can be satisfactorily accurate if replaced with a straight line (a), i.e. a system with one DOF with a constant dilatation $(\varepsilon)$ down the free end of the rope.

\subsection{Driving characteristics}

Drive, or the necessary movement of the device for vertical transport, can be modelled through a driving torque, Fig. 4a or through a so-called kinematic condition on the driving pulley, Fig. 4b.

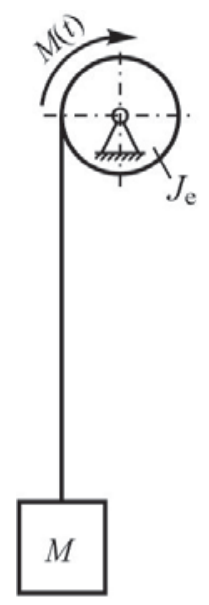

a)

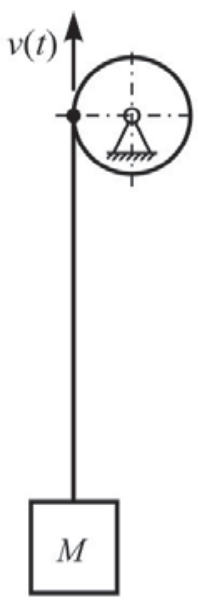

b)
Figure 4: Dynamic models of the drive, a) with a driving torque and $b$ ) with a lifting velocity

Because of the significant difference in stiffness of the ropes and elements of the driving mechanism, they can be observed as being absolutely stiff with the reduction of the mass and moments of inertia on the shaft of the pulley. If all the characteristics of the driving mechanism are known, it is possible to perform a dynamic analysis by setting the moments and inertia characteristics on the shaft of the pulley [6].

Boundary values of certain kinematic parameters are consequence of boundaries, which are characteristic for some machine types. The acceleration in cases when the elevators are used for people transport should not exceed $1 \mathrm{~m} / \mathrm{s}^{2}$, although, for example with slow elevators and when using asynchronous motors (with direct start), the maximum accelerations exceed the value of $1,4 \mathrm{~m} / \mathrm{s}^{2}$, and they can even go up to $2,5 \mathrm{~m} / \mathrm{s}^{2}$ [4]. With those elevators that have high velocities, special attention is paid to the "comfort of driving", so, in addition to the boundaries in velocity and acceleration, the value of the acceleration change over time, the so-called jerk, is limited as well. Fig. 5 shows the common diagrams of velocity, acceleration and jerk.

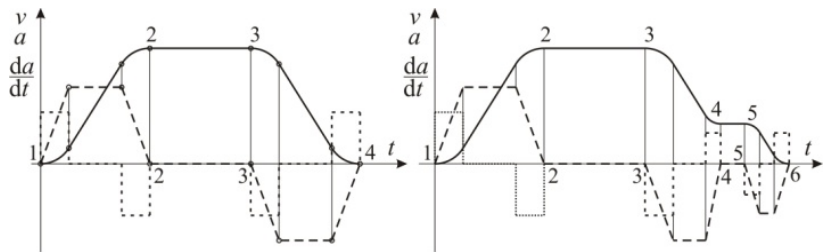

Figure 5: Examples of the diagram of movement for one (a) and two (b) velocities of motor

Modelling in kinematic conditions implies understanding the lifting velocity which in this paper is guaranteed by measuring the circumferential velocity of the pulley, at the point where the rope is meeting the driving pulley (calculated velocity, based on the measured value on the brake disc circumference).

2.3. Suitable dynamic model for the vertical transport machines

Based on the previous analysis, in the case of the vertical transport devices, with a driving pulley above the shaft, a suitable model for the dynamic analysis can be defined in the form given in Fig. 6.

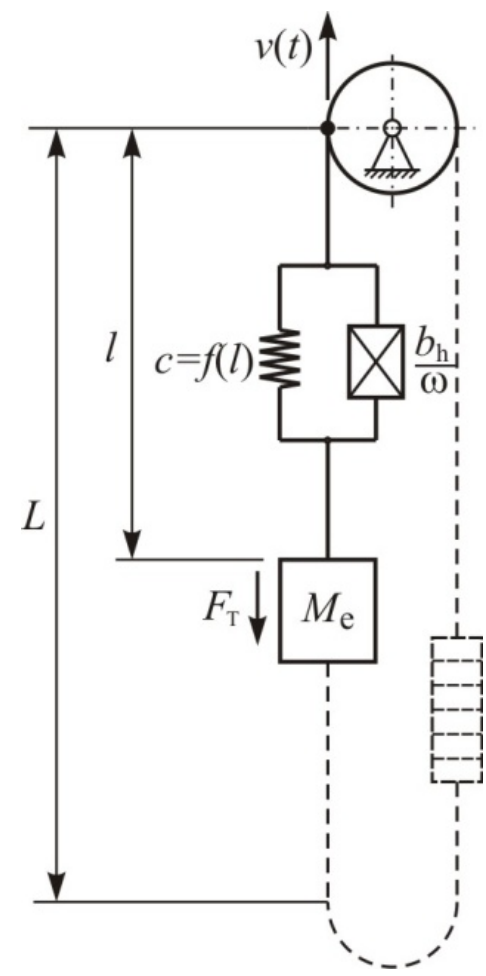

Figure 6: Suitable dynamic model for the analysis of the vertical transport machines

A suitable model represents an oscillatory system with one DOF, with the ropes that are described with an equivalent Kelvin's model where the stiffness during lifting is changed in accordance with the rope's free length while, at the same time, damping is of the hysteretic type with the friction of the guide rails included in it. The mass is taken as a constant for a specific oscillatory process, but different options are considered (an empty car, full car and the reduced rope weight). Defining the parameters for the 
model was performed by combining the well known theoretical relations for free oscillations with damping together with the measuring results of the mine elevator in RTB Bor.

The experimental results were obtained on the mine exploitation machine with the lifting capacity of $22 \mathrm{t}$. Its features are: mass of the empty cage $-13 \mathrm{t}$, mass of the counterweight (adjustable) $18 \div 23 \mathrm{t}, 6$ ropes $(27 \mathrm{~mm}$ diameter) with the mass per meter $\sim 15 \mathrm{~kg} / \mathrm{m}$. The lifting height is approximately $520 \mathrm{~m}$, and the lifting velocity of the cage is $4 \mathrm{~m} / \mathrm{s}$.

Computer simulations of the dynamic behaviour of the vertical transport machines are shown for four movement cases, with and without a load:

a) Movement of the "full cage" (with a locomotive, mass $\sim 11$ t) from the ground level to approximately the middle of the shaft $\sim 240 \mathrm{~m}$.

b) Movement of the full cage, with a locomotive, from the middle of the shaft downwards up to $\sim 480 \mathrm{~m}$.

c) Movement an empty cage from the middle of the shaft downwards up to $\sim 480 \mathrm{~m}$.

d) Movement of an empty cage from the position $\sim 480 \mathrm{~m}$ of the shaft up to 20 m upwards.

Fig. 7 shows schemes of those four cases after the pulley has stopped.

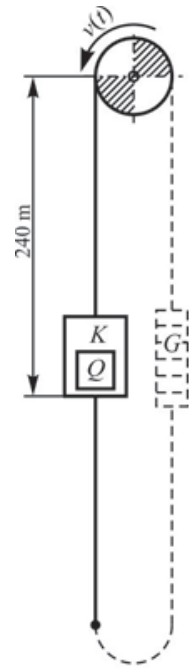

a)

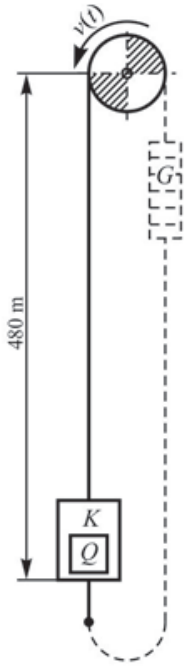

b)

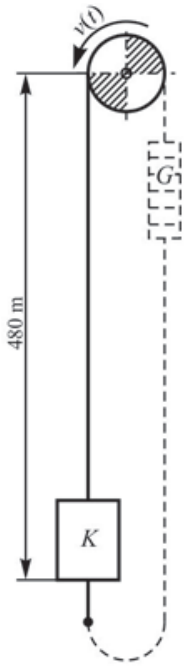

c)

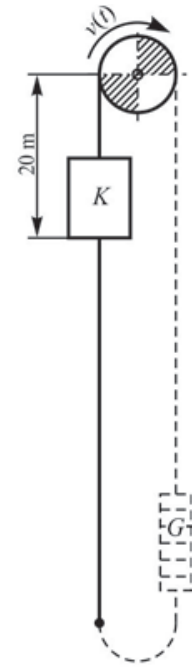

d)
Figure 7: Parameters of the mine elevator suitable for the analysis

\section{COMPUTER SIMULATIONS OF THE DYNAMIC BEHAVIOUR OF THE VERTICAL TRANSPORT MACHINES}

Since the dynamic model parameters have been defined, it is possible to conduct different simulations of the dynamic behaviour of machines for vertical transport by forming a differential equation of the motion and numeric integration using the different softwares. For our research we used software for an Automatic Dynamic Analysis of Mechanical Systems - MSC Adams. More details on the simulations and the possibilities of the software for the dynamic analysis of the system for vertical load lifting are provided in [6, 9].

Setting the motion in machines and facilities with vertical movement whose carrying (flexible) elements are winding onto a drum (steel ropes) is a problem which is not simple and easy to solve. Most software does not possess the tools to represent the carrying rope system the drum (driving pulley). In those cases it is necessary to use a combination of the existing tools to get satisfying results.

As it was previously explained in the second chapter, the driving characteristic is shown by setting the velocity, i.e. changes in the RPM of the driving pulley.

If we look at the problem of setting the function of the changes in the number of rotations of the electricmotor, we can do that in MCS Adams software by actually transforming that into setting the velocity in the time function for a certain marker on the rope in the direction in which the cage is being lifted. In that way, we are setting the motion on a translational joint, which can offer a simplified model of the connection between the rope and the driving pulley.

Defining the velocity as a function over the time can be done in a few ways. One of them is to define the velocity through a combination of a Heaviside step function with a cube polynomial, together with a linear dependence velocity-time [9].

The other way, which was used in this paper, was to set the velocity change in a form of "spline" which undoubtedly describes the change in the rotational velocity of a driving electric-motor which is in relation to the circumferential velocity of the drum, i.e. driving pulley, that was gained by direct measuring on the driving pulley by an incremental encoder. The "spline" used in the software, represents a medium line of the measured circumferential velocity of the driving pulley, which eliminates the so-called measure "frequency", Fig. 8.

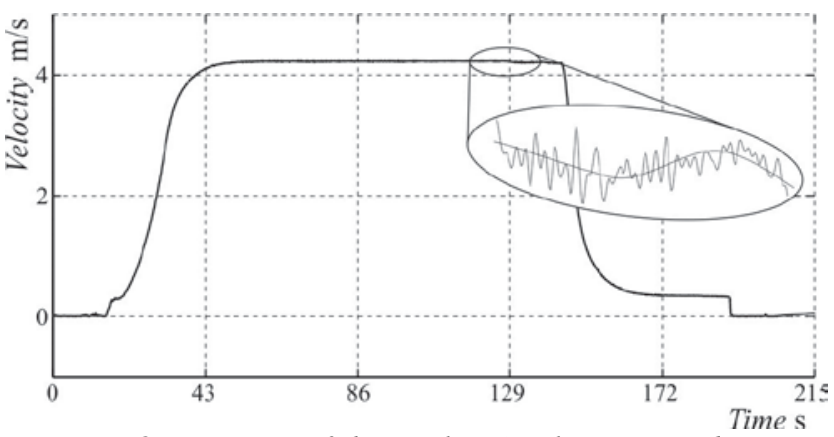

Figure 8: Forming of the "spline" velocity as a driving characteristic on the pulley

Fig. 9 shows the look of the dynamic model used for simulations in ADAMS, which corresponds to a dynamic model from chapter 2.3 .

In order to verify the dynamic model, there is a representation of enlarged oscillation periods after the complete stop of the pulley for the mentioned characteristic examples. They "overlap” with the diagrams obtained from measurings. 


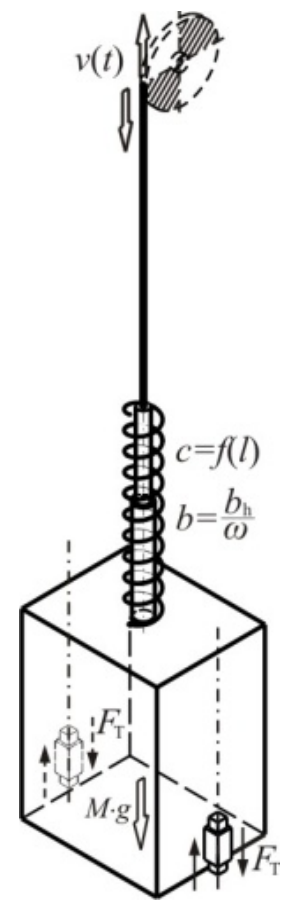

Figure 9: Computer model of exploitation facilities

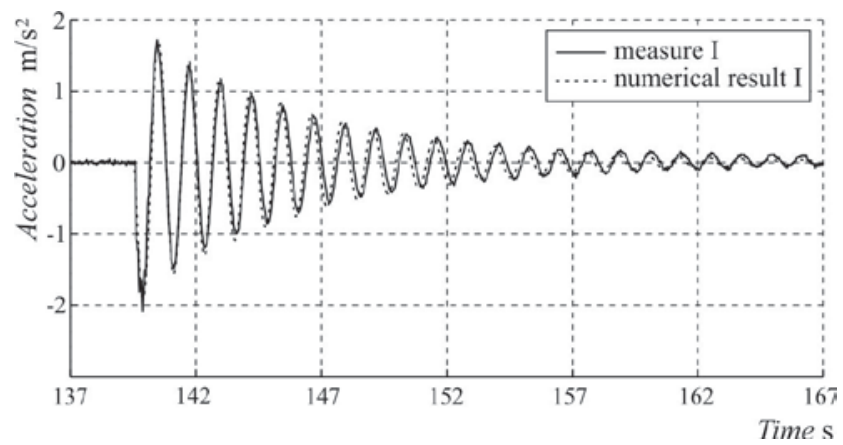

Figure 10: Diagrams of cage acceleration for example I (Fig. 7a)

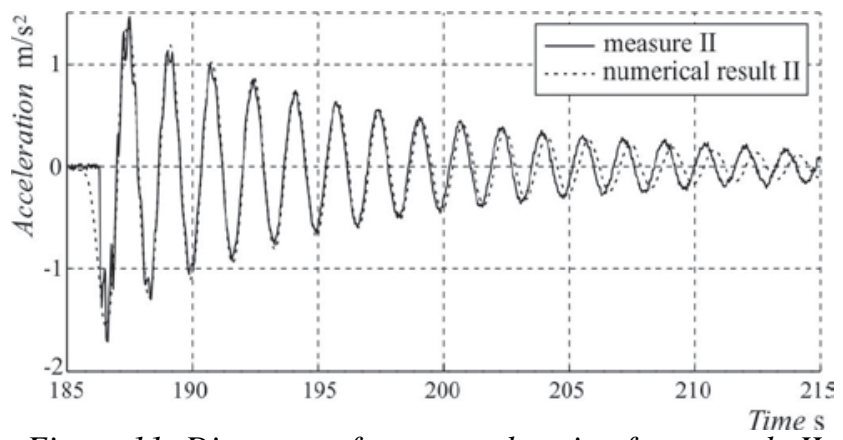

Figure 11: Diagrams of cage acceleration for example II (Fig. 7b)

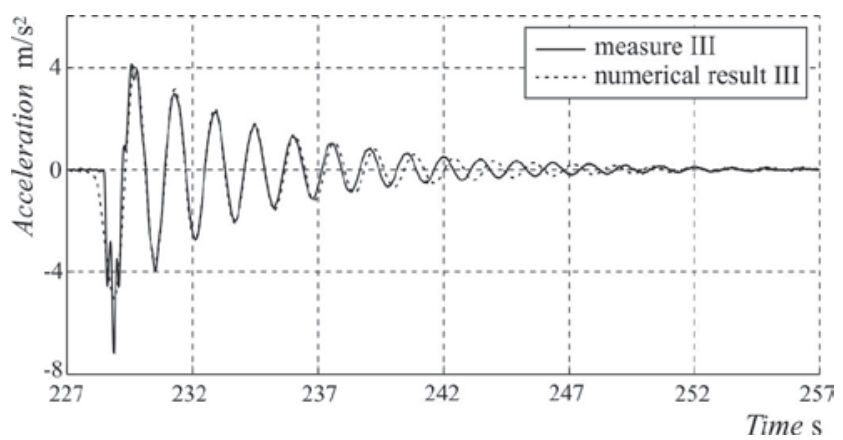

Figure 12: Diagrams of cage acceleration for example III (Fig. 7c)

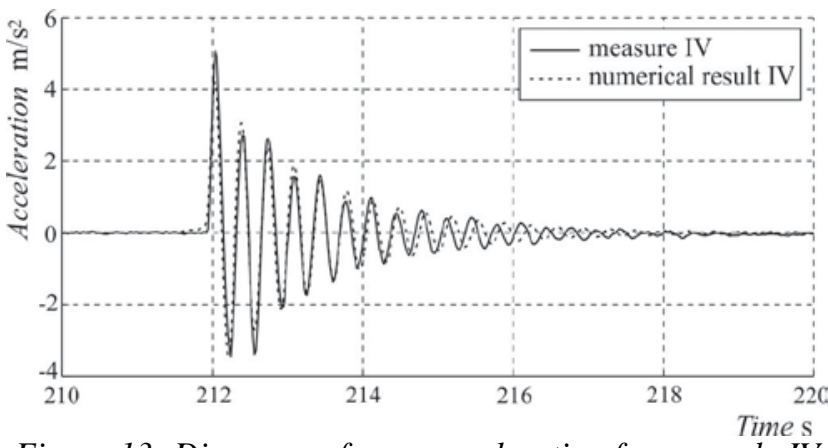

Figure 13: Diagrams of cage acceleration for example IV (Fig. 7d)

According to the previous diagrams it can be concluded that the dynamic model and the model parameters describe, with satisfying accuracy, the realistic behaviour of mine elevators, thus enabling their detailed analysis, which is not the purpose of this paper. As an illustration of the possibilities of dynamic analysis there is a diagram of the change of certain values drawn in the software for dynamic analysis (MSC Adams). In that case the change in stiffness and damping is included through a variable force between the marker on the pulley and the marker that show the connection between the ropes and the cage.

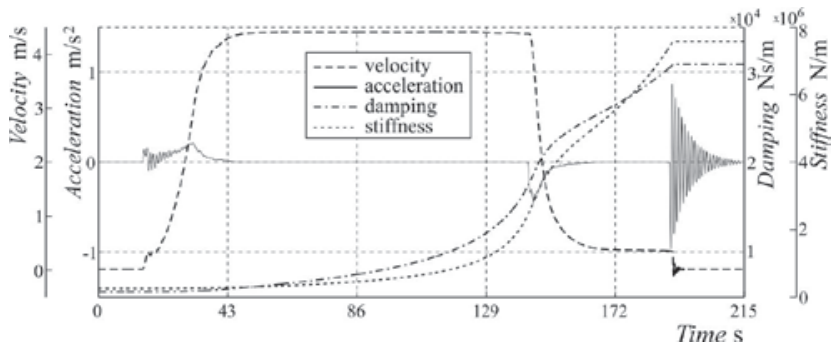

Figure 14: Diagram of the change in stiffness, damping, velocity and acceleration while lifting the cage

\section{CONCLUSION}

Dynamic analysis of the machines for vertical transport with large lifting heights (as $2000 \mathrm{~m}$ ), large carrying capacity and lifting velocities is of special interest because they define the quality basis for optimal projecting and their maintenance in relatively heavy working conditions.

Apart from the mentioned extreme parameters, the complexity of the dynamic analysis of these facilities is primarily due to these facts:

- The basic model is an oscillatory problem with an infinite number of DOF and it is influenced by a large number of factors.

- The driving torque is a variable value (the function of the pulley rotational speed and the operating load).

- The stiffness of the wire rope varies with the changes in the cage position, causing parametric oscillations,

- Steel rope elasticity modulus is not a constant value, as it is the case with homogenous bodies. It depends on rope structure, stress level and how long the rope was in service.

- Damping in the wire rope is a feature which has not been sufficiently examined. It is a consequence of the inner friction of a hysteretic type, depending on the construction of the rope, stress in the rope, contact type 
and friction between the wires, then lubrication, oscillation amplitudes etc.

- The influence of friction in the guide rails on the damping of the whole system cannot be ignored.

The system with an infinite number of DOF has come down to a system with one DOF and a forced movement which was modelled according to the velocity measured on the pulley. It is also possible to replace the rope system with the equivalent Kelvin's model with variable stiffness $(c=E A / 1)$ and damping. By combining theoretical analysis with an experimental procedure it is possible to define the real values of elasticity modulus and damping, with the results of measuring the oscillation periods and amplitudes at the moment when the driving pulley is stopped. In order to obtain more reliable results and a more detailed analysis of stiffness and damping in such facilities, greater measuring should be conducted in both real and laboratory conditions. It should be taken into consideration even though the basic model is very simplified, the analysis of a formed dynamic model, due to its variable parameters, can be realised only with the usage of numeric methods or suitable software.

\section{REFERENCES}

[1] K. Feyrer, "Wire Ropes”, University of Stuttgart, Germany, (2007)

[2] C. W. Silva, "Vibration, Damping, Control and Design”, CRC Press - Taylor \& Francis Group, Boca Raton, Florida, (2007)
[3] J. N. Vergne, “The Hard Rock Miner’s Handbook, Edition 3”, McIntosh Engineering Limited, Ontario, Canada, (2003)

[4] J. Vladić, "Prilog određivanju stepena sigurnosti protiv proklizavanja dinamički opterećenog užeta u sistemu prenosa snage pogonskom užnicom”, Magistarski rad, Novi Sad, (1982)

[5] B. Vujanović, “Teorija oscilacija”, Univerzitet u Novom Sadu, (1995)

[6] R. Đokić, "Razvoj analitičko-numeričkih postupaka za određivanje dinamičkog ponašanja liftova", Magistarski rad, Novi Sad, (2010)

[7] I. Herrera, H. Su and S. Kaczmarczyk, "Investigation into the damping and stiffness characteristics of an elevator car system”, Applied Mechanics and Materials, 24-25, pp. 77-82, (2010)

[8] M. Pakdemirli and A.G. Ulsoy, "Stability analysis of an axially accelerating string”, Journal of Sound and Vibration 203, 5, pp 815-832, (1997)

[9] J. Vladić, R. Đokić, M. Kljajin and M. Karakašić, "Modelling and simulations of elevator dynamic behaviour”, Tehnički vjesnik/Technical Gazette, Vol. 18, No.3, pp. 423-434, (2011)

[10] J. Vladić, P. Malešev, R. Šostakov and N. Brkljač, "Dynamic analysis of the load lifting mechanisms", Strojniški vestnik 54, 10, pp. 655-661, (2008) 